\title{
Influx of African biomass burning aerosol during the Amazonian dry season through layered transatlantic transport of black carbon-rich smoke
}

Bruna A. Holanda et al.

Correspondence to: Mira L. Pöhlker (m.pohlker@mpic.de) and Christopher Pöhlker (c.pohlker@mpic.de)

The copyright of individual parts of the supplement might differ from the CC BY 4.0 License. 
2 Table S1. List of time sections in which the UPL, CL, LPL MBL and BB were sampled during 3 flight AC19.

4

\begin{tabular}{lll}
\hline & \multicolumn{2}{c}{ Time window } \\
\hline Offshore profile & $16: 50: 00$ & $19: 07: 00$ \\
\hline PPL & $16: 21: 50$ & $16: 22: 40$ \\
& $16: 54: 22$ & $16: 55: 02$ \\
$17: 08: 22$ & $17: 09: 00$ \\
$18: 02: 46$ & $18: 03: 09$ \\
$18: 03: 47$ & $18: 04: 18$ \\
& $18: 10: 35$ & $18: 12: 15$ \\
$18: 34: 32$ & $18: 35: 47$ \\
& $18: 42: 51$ & $18: 43: 39$ \\
& $18: 47: 50$ & $18: 48: 04$ \\
& $19: 58: 00$ & $19: 58: 39$ \\
\hline CL & $17: 09: 08$ & $17: 09: 30$ \\
& $18: 02: 04$ & $18: 02: 39$ \\
& $18: 36: 08$ & $18: 38: 42$ \\
& $18: 40: 16$ & $18: 42: 44$ \\
$18: 43: 43$ & $18: 44: 24$ \\
& $18: 47: 21$ & $18: 47: 43$ \\
\hline LPL & $16: 52: 03$ & $16: 53: 18$ \\
& $17: 10: 00$ & $17: 11: 37$ \\
& $17: 56: 43$ & $17: 57: 16$ \\
& $17: 57: 33$ & $17: 58: 15$ \\
& $17: 58: 31$ & $18: 00: 08$ \\
& $18: 54: 33$ & $18: 55: 51$ \\
\hline MBL & $17: 23: 14$ & $17: 27: 28$ \\
\hline BB & $19: 24: 03$ & $19: 24: 37$ \\
& $19: 24: 49$ & $19: 25: 08$ \\
& $19: 25: 44$ & $19: 27: 02$ \\
& $19: 27: 11$ & $19: 28: 16$ \\
& $19: 30: 09$ & $19: 30: 46$ \\
& $19: 32: 24$ & $19: 34: 03$ \\
$19: 18: 24$ & $19: 18: 45$ \\
\hline & & \\
& & \\
& &
\end{tabular}




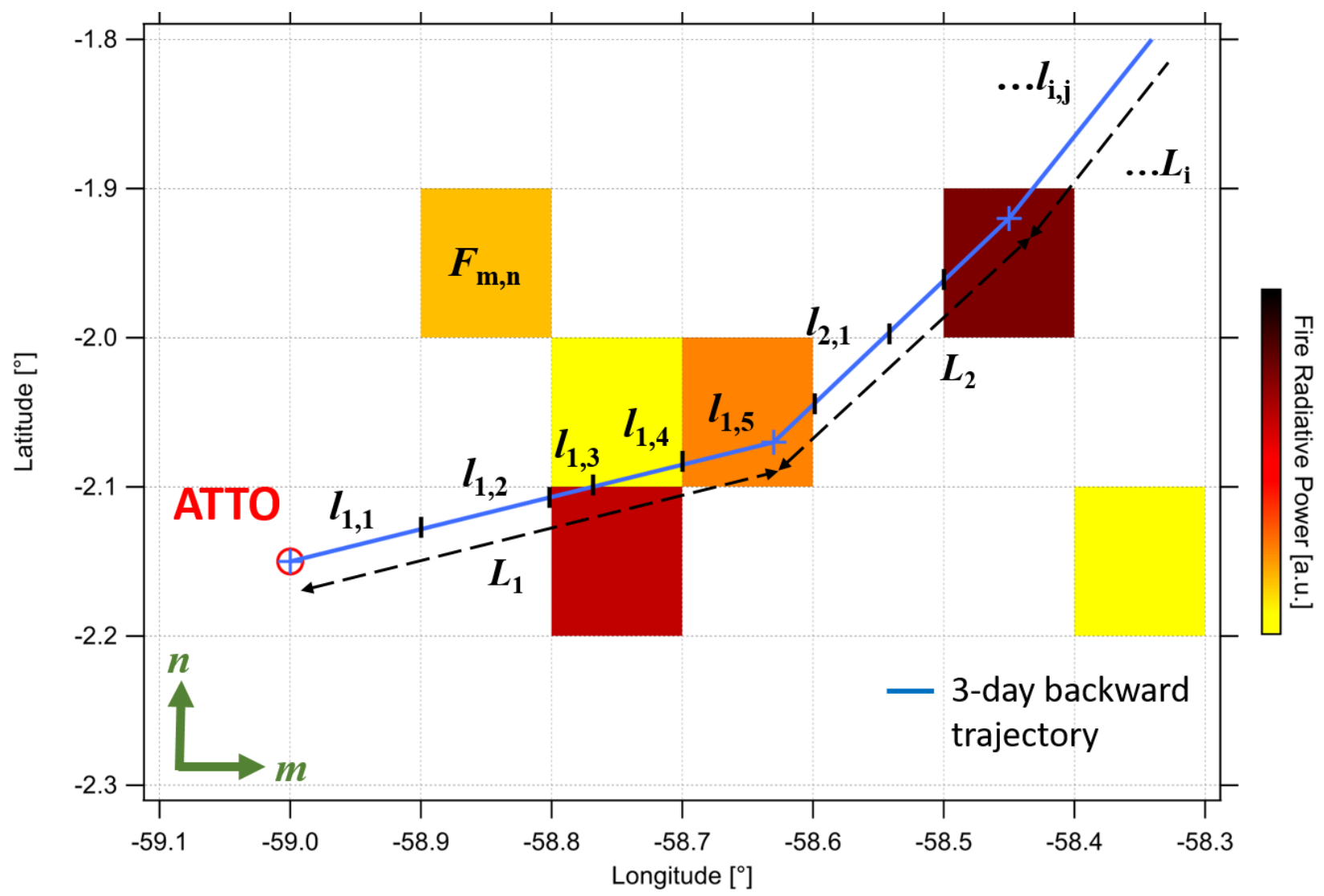

7 Figure S1. Sketch illustrating the initiation of a three-day BT starting at the ATTO site (red 8 circle) mapped to the raster of fire intensities. 


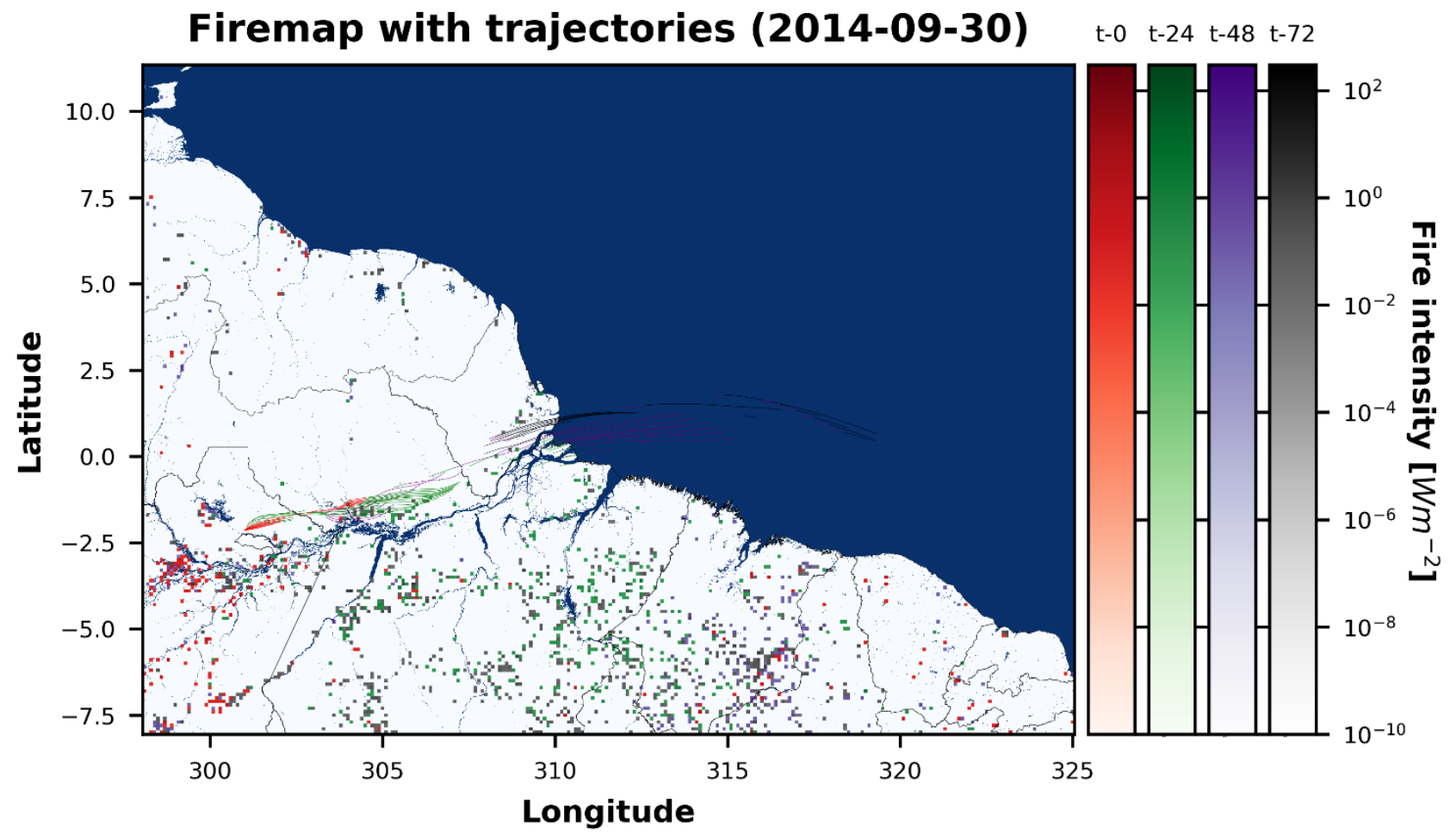

9

10 Figure S2. Ensemble of three-day HYSPLIT BTs, starting at every hour at the ATTO site (1000

11 m a.s.1.) on 30 September 2014 and corresponding daily fire intensity maps ( $\left.\mathrm{W} \mathrm{m}^{-2}\right)$ from the

12 Global Fire Assimilation System (GFAS). 


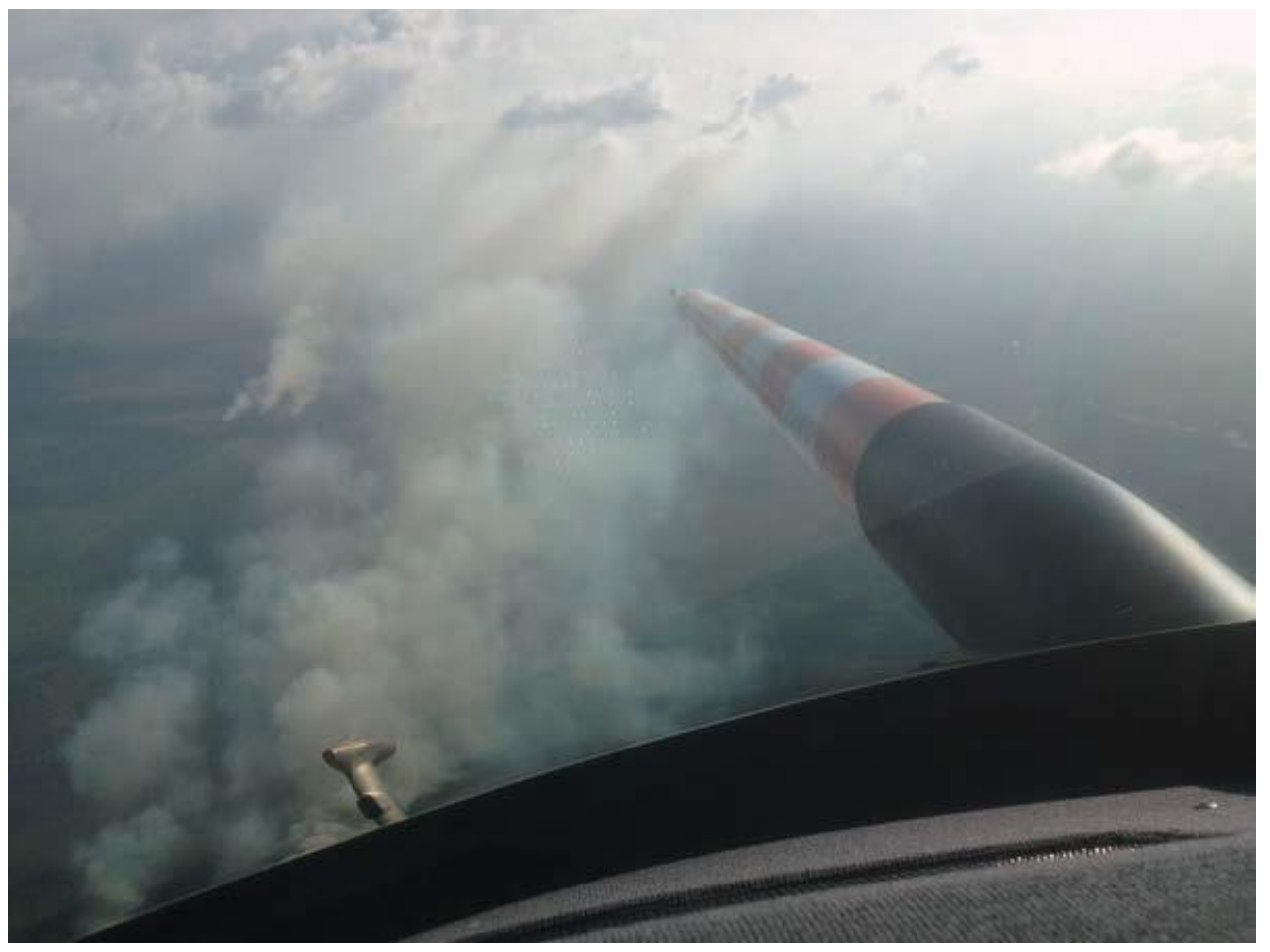

14 Figure S3. View from the HALO cockpit, showing the active fire plumes (intersected at $\sim 1 \mathrm{~km}$ 15 above ground) during flight AC19 at 19:20 UTC on 30 September 2014. See also fire map in Fig. 161. 


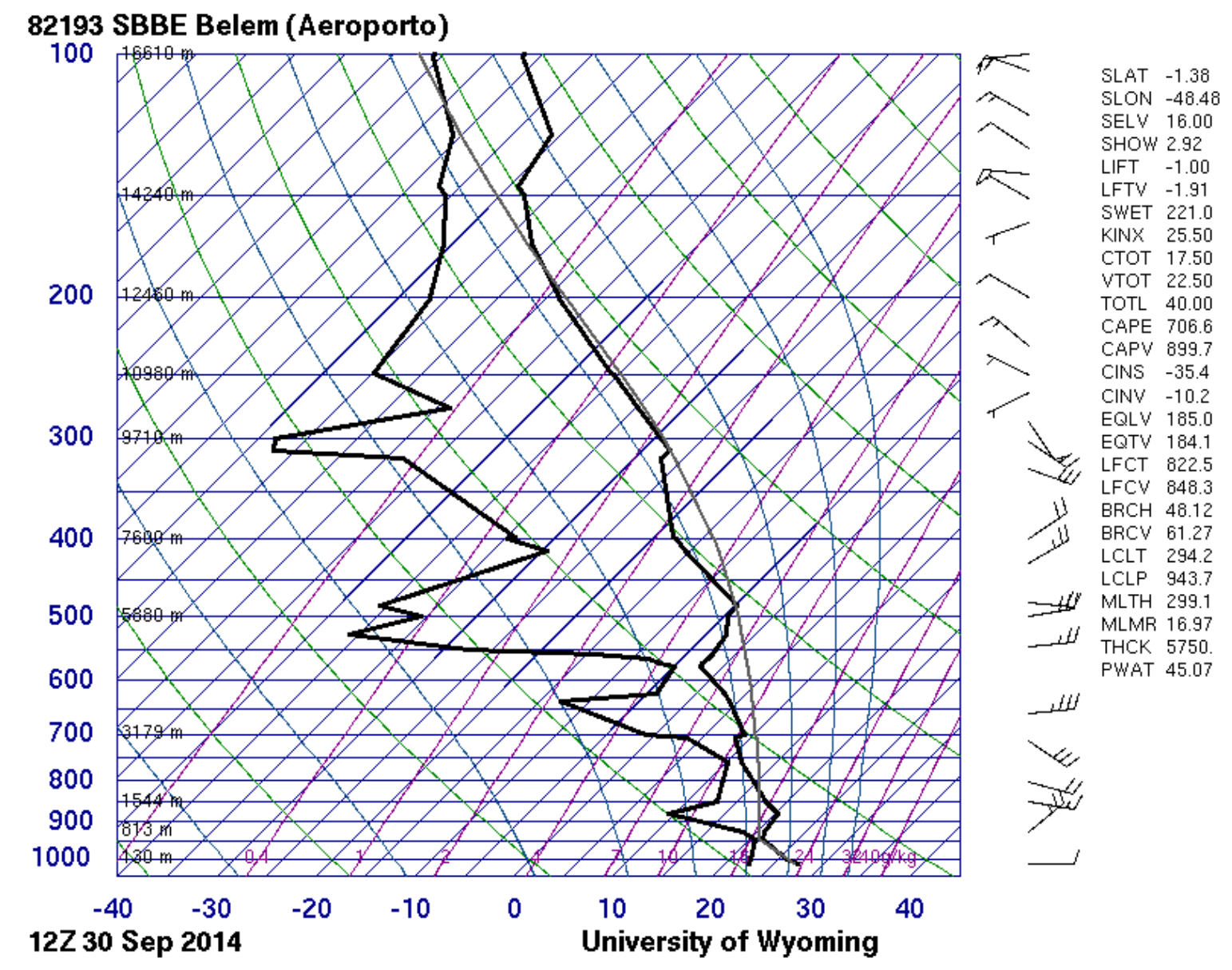

18 Figure S4. Radiosonde sounding at Belem Airport (see Fig 1.) on 30 September 2014 at 12:00

19 UTC, provided Wyoming University (http://weather.uwyo.edu/upperair/sounding.html, last

20 access on 06 August 2019). The sounding shows similar tropospheric stratification as presented

21 in Fig. 3. The first layer (top around $1000 \mathrm{~m}$ ) is associated with the boundary layer, the second

22 (top around $3200 \mathrm{~m}$ ) is related to the shallow clouds top and the third one (around $5000 \mathrm{~m}$ ) is the 23 large scale inversion. 


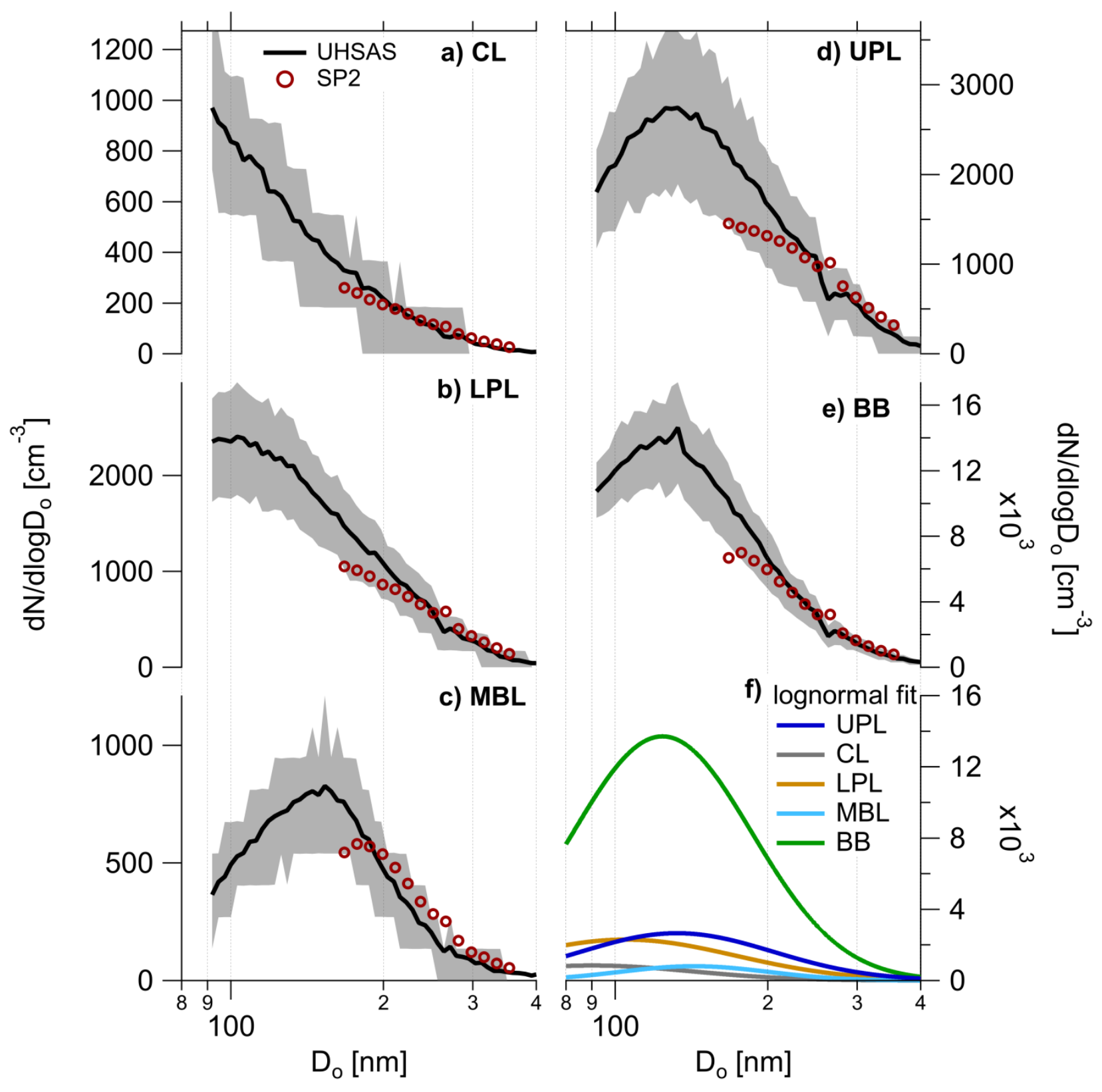

25 Figure S5. Particle number size distributions (median and interquartile range) derived from the 26 UHSAS and SP2 (rBC + SC) for the (a) CL, (b) LPL, (c) MPL, (d) UPL and (e) fresh BB plume 27 probed during flight AC19. Panel (f) shows the curve fits of the UHSAS data points. 


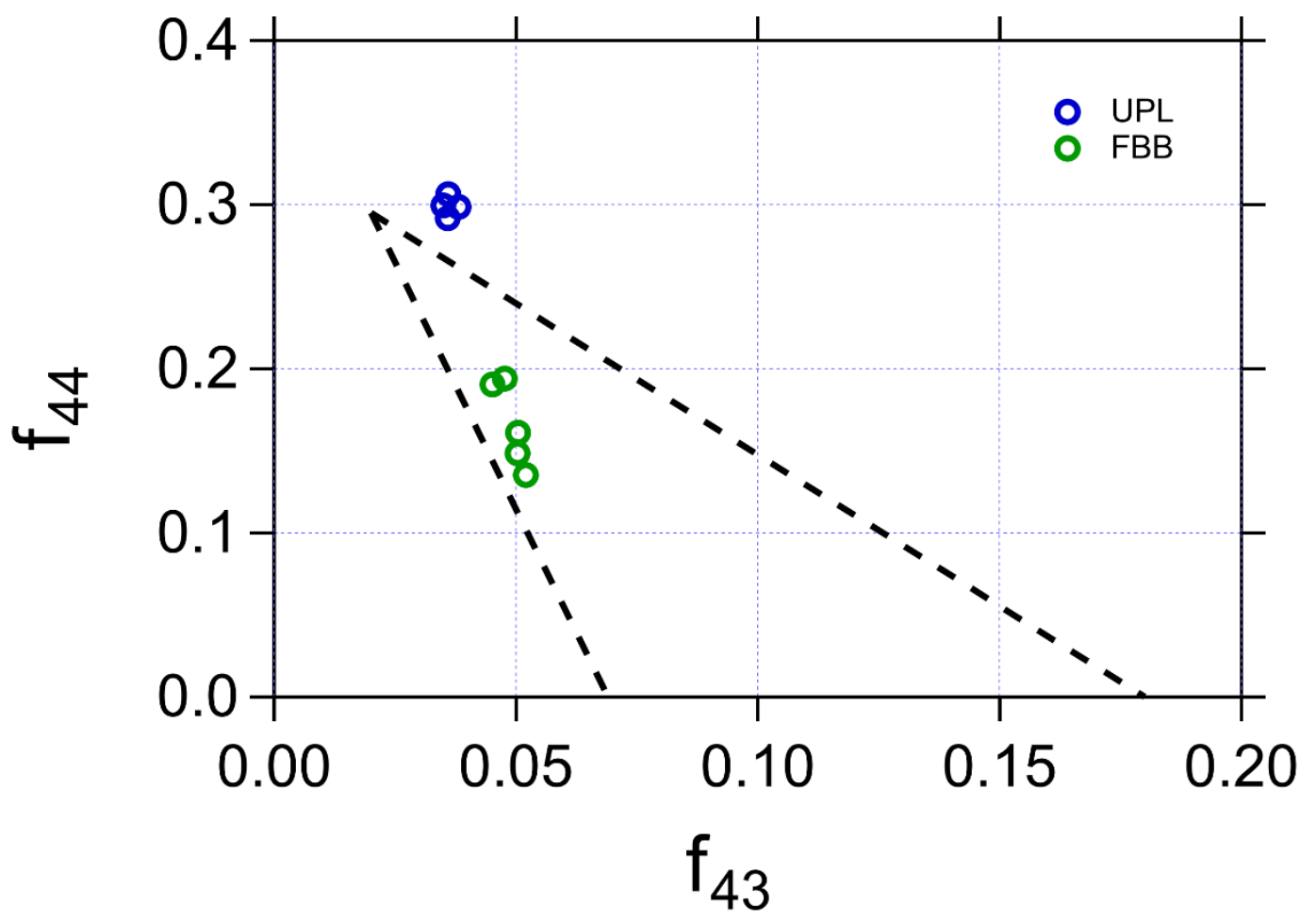

Figure S6. Scatterplot of the ratios $\mathrm{f}_{43}\left(\mathrm{~m} / \mathrm{z} 43\right.$ to total organic signal) against $\mathrm{f}_{44}(\mathrm{~m} / \mathrm{z} 44$ to total organic signal) expressing the photochemical aging of the organic aerosol measured by the C-ToF-AMS. The blue and green markers correspond to measurements within the UPL and fresh $\mathrm{BB}$, respectively. The signal at $\mathrm{m} / \mathrm{z} 44$ relates mostly to $\mathrm{CO}_{2}{ }^{+}$ ions and the $\mathrm{m} / \mathrm{z} 43$ signal to $\mathrm{C}_{2} \mathrm{H}_{3} \mathrm{O}^{+}$ions. The triangular region (dashed lines) in the $\mathrm{f}_{44}$ vs. $\mathrm{f}_{43}$ space defines the boundaries within which most of the organic aerosol was found in previous studies and can be used as a guide to characterize oxidized organic components: data in the upper left represent more oxidized organics vs. the less oxidized organics in the lower right (Ng et al., 2010; Schulz et al., 2018). 


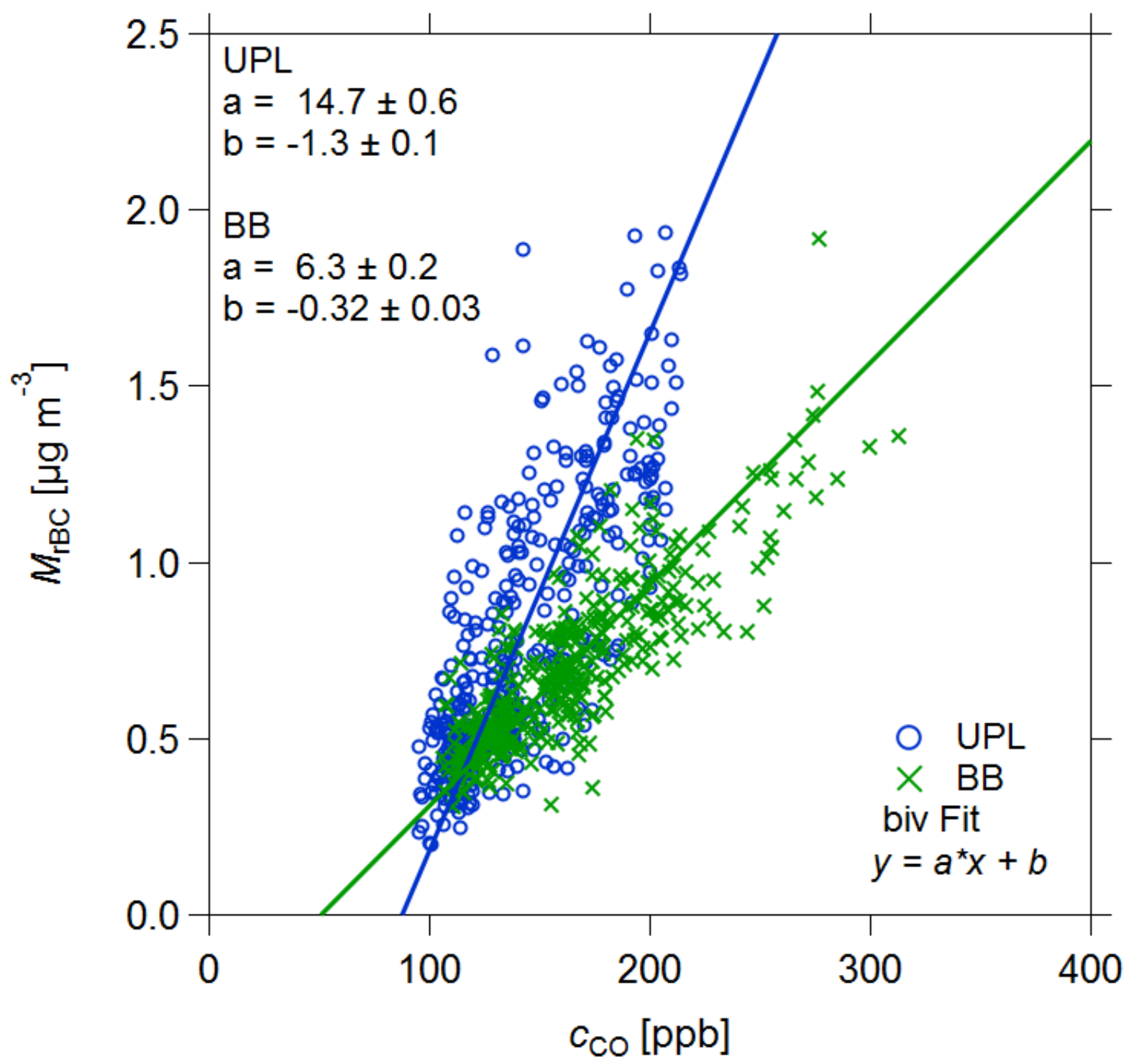

39

Figure S7. Correlation between $\Delta c_{\mathrm{CO}}$ and $\Delta M_{\mathrm{rBC}}$ within the upper pollution layer (UPL) and fresh

41 biomass burning (BB) plume probed during AC19. A bivariate regression fit was applied to the

42 data set in order to obtain the $\mathrm{BC}$ enhancement ration, $E n R_{\mathrm{BC}}$. 

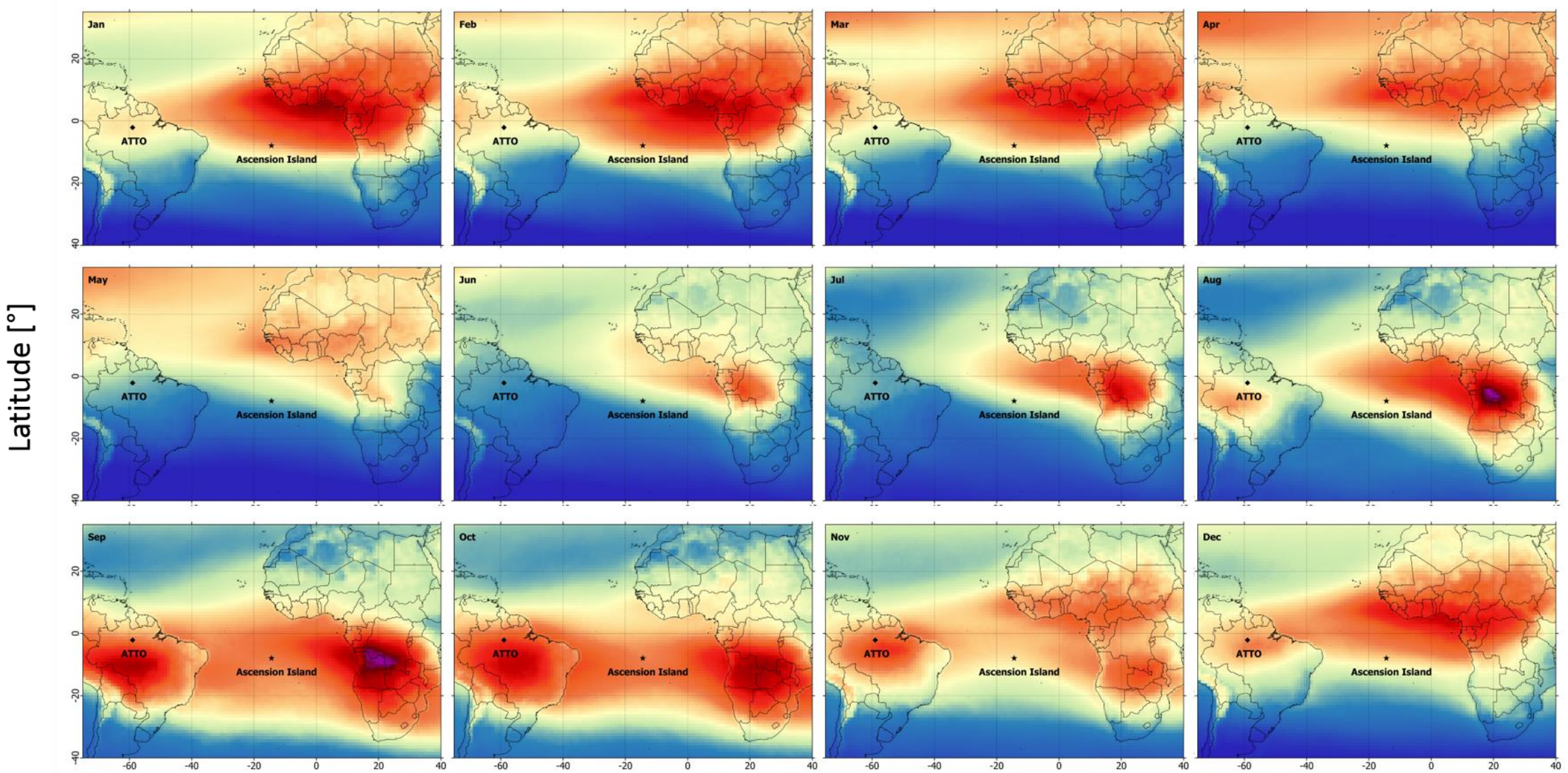

Longitude $\left[{ }^{\circ}\right]$

43

44 Figure S8. Monthly distribution of AIRS-derived carbon monoxide (400 to $600 \mathrm{hPa}$ ) over the Southern Hemisphere. The map shows

45 averages over multiple years (2005-2018). 


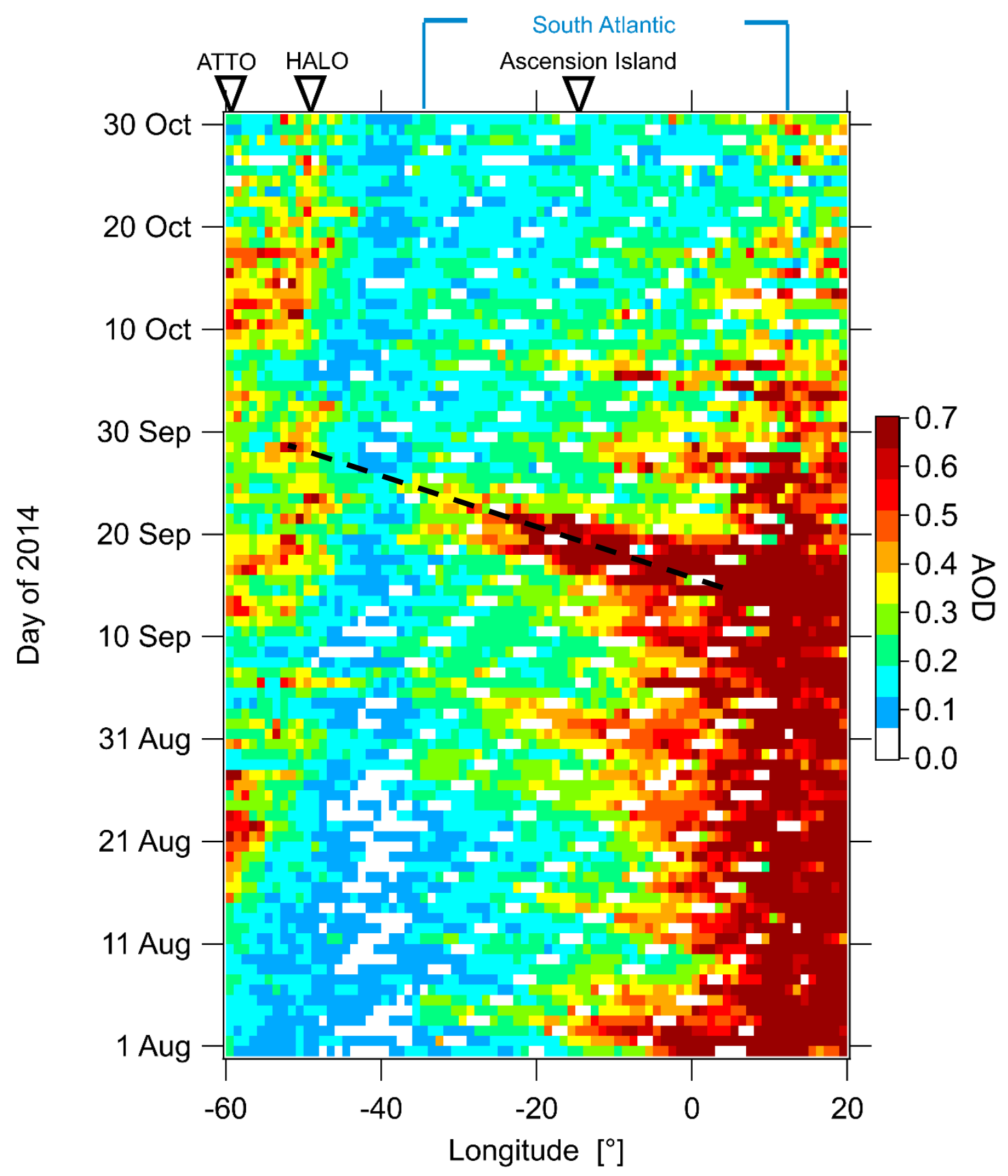

Figure S9. Hovmöller plot of the daily MODIS AOD $(550 \mathrm{~nm})$ distributed over the South

48 Atlantic region $\left(60^{\circ} \mathrm{W}\right.$ to $\left.20^{\circ} \mathrm{E}\right)$ from August to October 2014 , averaged over the latitudinal band

49 of $10^{\circ} \mathrm{S}$ to $5^{\circ} \mathrm{N}$, corresponding to the region of interest (ROI) highlighted in Fig. 7a. Several

50 events of transatlantic transport of aerosol from Africa towards South America can be easily

51 identified, with the strongest plume starting approximately on 15 September 2014. A dashed line

52 for this particular event is also shown in the picture, which arrives at a time close to our

53 observations on AC19 on 30 September 2014. Westwards of $35^{\circ} \mathrm{W}$, the AOD levels are 
54 increasingly influenced by the South American continent, which masks the AOD signals of the 55 transported African pollution as it approaches the South American continent. 


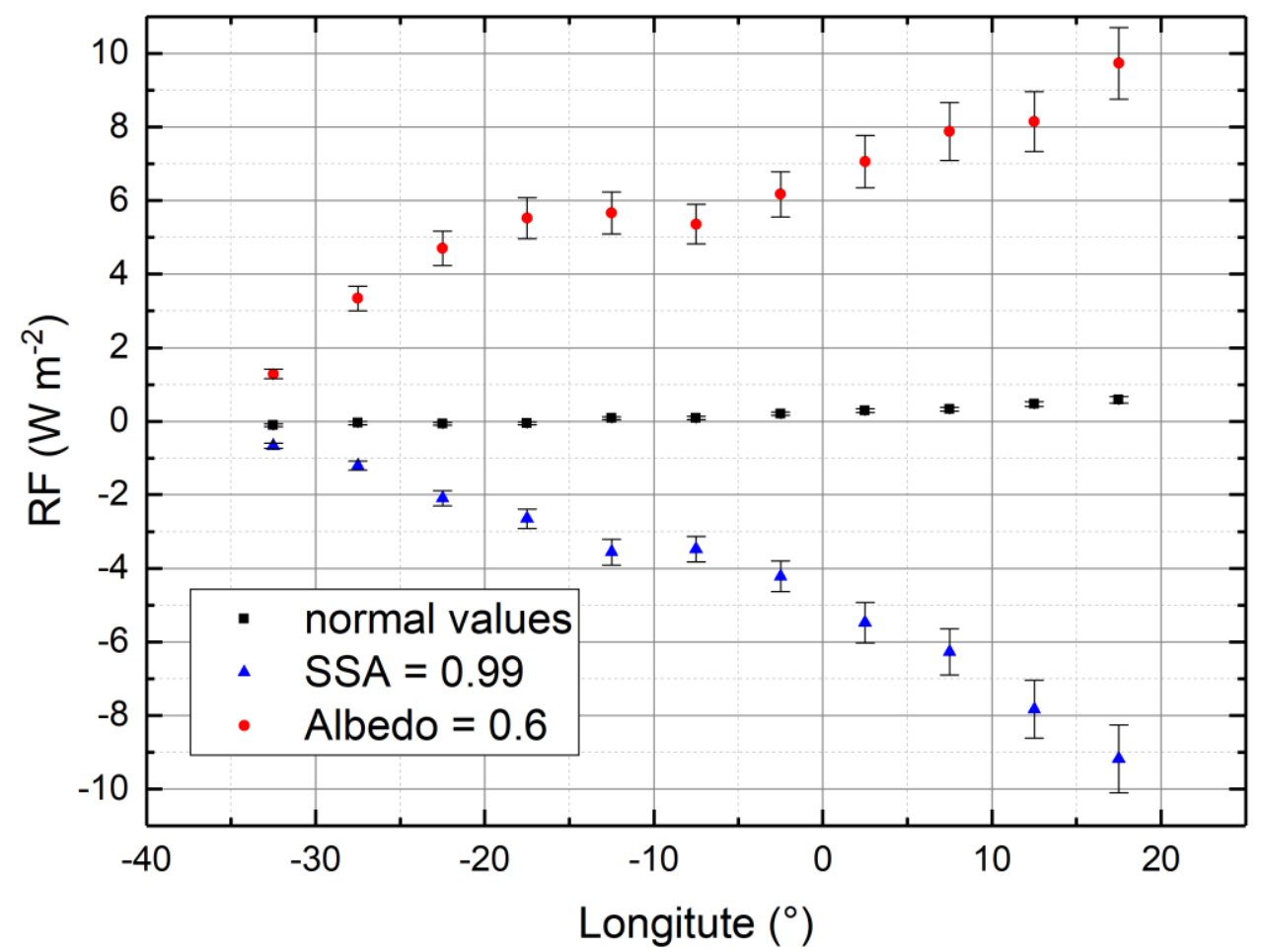

56

57 Figure S10. Sensitivity tests showing the DRF-TOA changes due to different assumptions in the

58 aerosol and surface properties, comparing with the original DRF-TOA estimation. The

59 simulations show that if the aerosol layer is mostly scattering $(\mathrm{SSA}=0.99)$, a general cooling

60 (back-scattering by the layer) is observed. On the other hand, if the absorbing ocean is replaced

61 by a higher surface albedo (0.6), a warming effect by the layer is observed due to the downward

62 radiation that is scattered back and forth between the aerosol layer and the surface. 